\title{
High intensity and red enriched LED lights increased the growth of lettuce and endive
}

\author{
Monica Flores, ${ }^{1}$ Miguel Urrestarazu, ${ }^{2}$ Asuncion Amorós, ${ }^{3}$ Victor Escalona ${ }^{1,4}$ \\ ${ }^{1}$ Postharvest Studies Center, Faculty of Agricultural Sciences, University of Chile, Santiago, Chile; ${ }^{2}$ Soilless \\ culture laboratory, CIAIMBITAL, University of Almería, Almería, Spain; ${ }^{3}$ Department of Applied Biology, \\ Universidad Miguel Hernández de Elche, Orihuela, Alicante, Spain; ${ }^{4}$ Department of Agricultural \\ Production, Faculty of Agricultural Sciences, University of Chile, Santiago, Chile
}

\author{
Highlights \\ - $\quad$ The spectra of LED affected leaf number in lettuce and endive. \\ - $\quad$ S2 spectrum improved growth parameters of both leafy vegetables. \\ - Light intensity improved growth parameters of both leafy vegetables. \\ - Antioxidant compound contents were significantly increased by high intensity LED light.
}

\begin{abstract}
Changes in plant responses have been associated with different fractions of the visible spectrum and light intensity. Advances in light-emitting diodes (LED) have enabled the study of the effect of narrow wavelengths on plant growth and antioxidant compound synthesis. LED technology also facilitates the incorporation of
\end{abstract}

Correspondence: Victor Escalona, Department of Agricultura Production, Faculty of Agricultural Sciences, University of Chile. Santa Rosa 11315, La Pintana, P.O. Box 1004, Santiago, Chile.

E-mail: vescalona@uchile.cl

Key words: Light-emitting diodes; indoor growth; leafy vegetables; phenolic compounds; vertical farming.

Acknowledgements: the authors are grateful to project FIC 30474703 0 (Región del Libertador General Bernardo O'Higgins, Chile) for financial support and to $\mathrm{PhD}$ scholarship $\mathrm{N}^{\circ} 21150786$ (ANID-Chile) and CeiA3, Erasmus mobility and REDES 190057 (ANID, Chile) awarded to Mónica Flores. In addition, we wish to thank the Spanish Ministry of Science, Innovation and Universities for the national mobility scholarship for professors and senior researchers $N^{\circ}$ PRX19/00138 granted to Prof. Asunción Amorós.

Contributions: MU, VHE, conceptualisation and methodology design; MF, MU, data acquisition: MF, MU, VHE, AA, data analysis; MF, VHE, AA, writing and editing.

Received for publication: 19 May 2021.

Revision received: 9 November 2021.

Accepted for publication: 28 November 2021.

(C) Copyright: the Author(s), 2022

Licensee PAGEPress, Italy

Italian Journal of Agronomy 2022; 17:1915

doi:10.4081/ija.2021.1915

This article is distributed under the terms of the Creative Commons Attribution Noncommercial License (by-nc 4.0) which permits any noncommercial use, distribution, and reproduction in any medium, provided the original author(s) and source are credited. light sources in a controlled setting where light spectra and intensity can be regulated. The objective of this study was to compare the effect of two commercial light spectra (S1: standard white light with $32.8 \%$ blue, $42.5 \%$ green, $21.7 \%$ red, and $2.4 \%$ far-red; S2: AP67 spectrum, designed for horticultural growth, with $16.9 \%$ blue, $20.5 \%$ green, $49.7 \%$ red and $12.3 \%$ far red) at two light intensities [low intensity $\left(78 \mu \mathrm{mol} \cdot \mathrm{m}^{-2} \mathrm{~s}^{-1}\right.$ of photons for $\mathrm{S} 1$ and $62 \mu \mathrm{mol} \cdot \mathrm{m}^{-2} \mathrm{~s}^{-1}$ for $\mathrm{S} 2$, and high intensity (HI) (102 and 100 $\mu \mathrm{mol} \cdot \mathrm{m}^{-2} \mathrm{~s}^{-1}$ for $\mathrm{S} 1$ and $\mathrm{S} 2$, respectively)] on growth and antioxidant compound contents in two leafy vegetables: endive (Cichorium endivia L.) and lettuce (Lactuca sativa L.). Fresh weight (FW), dry weight (DW), and DW\% of plants were taken as growth indicators. In addition, leaf number, soil plant analysis development index, leaf area (LA), and specific leaf area were also evaluated. Antioxidant synthesis was measured as total phenol content, total flavonoid content, and antioxidant activity. The results showed that $\mathrm{S} 2$ and $\mathrm{HI}$ increased the FW, DW, and LA in both species. On the other hand, antioxidant compound contents were significantly increased by HI but did not vary with the spectrum.

\section{Introduction}

According to the Food and Agriculture Organisation (FAO) data, worldwide endive and lettuce production reached $26,375,002$ tons in 2015 and increased to 29,134,653 tons in 2019, occupying an area from $1,223,238$ ha to $1,316,028$ ha, respectively (FAO, 2020). China was the main producer in 2019 with $16,314,499$ tons, followed by the USA with $3,688,520$ tons, and India with a production of $1,262,702$ tons in the same year. In fourth place, Spain reached 1,009,710 tons of endive and lettuce with $3.5 \%$ of the world's production (FAO, 2020).

Traditional agriculture takes place in an open field or a greenhouse. If plants are grown in an open field, yield and quality are subject to weather conditions. By contrast, in a greenhouse, despite some parameters like temperature and relative humidity being regulated, others like light quality and intensity cannot be, which impedes the energy optimisation of the growing environment (Kozai and Niu, 2016).

Light is one of the leading environmental factors that regulate plant growth and development (Fan et al., 2013; Huché-Thélier et 
al., 2016). It provides the energy for photosynthesis and induces different physiological responses, including seed germination, phototropism, chloroplast movement, shade avoidance, circadian rhythms, flowering time, and morphogenesis (Son and Oh, 2013, 2015; Hasan et al., 2017). In addition, light has different components that serve as a signal stimulus, including light intensity, light quality or spectrum, and day length (Son and Oh, 2013, 2015; Urrestarazu et al., 2016).

Light intensity is essential for optimal plant growth. However, it has been shown that high light intensities can be detrimental and reduce plant production. This can reduce leaf area and specific leaf area (SLA) and cause leaves to wilt because it affects chlorophyll content and photosynthetic efficiency (Shirke and Pathre, 2003; Fan et al., 2013). If the intensity is high enough, it can destroy the photosynthetic system and cause severe oxidative damage to leaf tissue (Farquhar and Sharkey, 1982). By contrast, low intensities can also cause changes in the morphology and physiology of the leaf. In this case, it may lead to increased SLA and plant height (Fan et al., 2013). Finally, it has been proved that plants have different lighting requirements under artificial light than under sunlight (Liu et al., 2010; Yao et al., 2017); therefore, it is crucial to find the best light intensity to optimize plant growth under indoor conditions.

Different light components affect different plant growth parameters. Thus, red light accelerates growth speed, with greater leaf area and increased biomass accumulation (Tosti et al., 2018). In addition, the same authors, mentioned that red light has a greater absorption of radiation, efficiency in the use of radiation, and efficiency in the conversion of energy into biomass.

Different light components affect the growth and plant development and the biosynthesis of primary and secondary metabolites during the growing period (Liu et al., 2016). Ebisawa et al. (2008) and Colonna et al. (2015) showed that spectrum and intensity were fundamental to maximising secondary metabolite accumulation. Among secondary metabolites, phenolic acids and flavonoids stand out because they play an important role as antioxidants that can protect consumers against some types of cancer and cardiovascular diseases (Pérez-López et al., 2018). Flavonoid biosynthesis, in particular, is strongly influenced by light quality (Ebisawa et al., 2008). Thus, an optimal light condition is vital for obtaining antioxidant-enriched vegetables.

Plant processes are also affected by the light spectrum. They perceive light signals through photoreceptors such as phytochromes, which absorb red and far-red light, and cryptochromes or phototropins, which absorb in the blue and ultraviolet A (UV-A) region of the spectrum (Son and Oh, 2015). Specifically, red light (between 600 and $700 \mathrm{~nm}$ ) and blue light (400 and $500 \mathrm{~nm}$ ) can affect plant morphology, physiology and development, photosynthesis, and primary and secondary metabolism (Hasan et al., 2017; Bartuca et al., 2020). The use of the blue or red LED spectrum has resulted in a significant enhancement in the quality and yield of fruits and vegetables (e.g., cucumber, pepper, and strawberry) compared to white fluorescent light or sunlight (Hao et al., 2012; Sabzalian et al., 2014; Choi et al., 2015).

Improvements in light technology, particularly with the development of light-emitting diodes (LED), have simplified the study of plant responses in a specific spectral region (Snowden et al., 2016; Hasan et al., 2017). LEDs have the advantage of high lightconversion efficiency with low radiant heat output. In addition, LEDs are available in various narrow wavelengths, so it is possible to optimize light spectrum and intensity to improve yield and quality (Son and Oh, 2013; Hasan et al., 2017).

Nowadays, blue and red LEDs are usually used for plant growth, yet the effects of spectral quality on plant development and secondary metabolite synthesis are not entirely understood.

This study aimed to compare the effect of two commercial light LED spectra (S1: white light and S2: AP67 spectrum, designed for horticultural growth) at two light intensities (LI: low and $\mathrm{HI}$ : high intensity) on agronomic parameters and antioxidant compound contents in endive (Cichorium endivia L. cv. Crispum Rizada) and lettuce (Lactuca sativa L. cv. Romana Long Blonde Galaica) plants.

\section{Materials and methods}

\section{Plant material, growing conditions, and light treat- ments}

Endive cv. Crispum Rizada and lettuce cv. Romana Long Blonde Galaica were used as plant material. The seed company recommends that both cultivars be grown in spring-summer periods (Semillas Fitó ${ }^{\mathrm{TM}}$, Barcelona, Spain).

One seed per socket was sown in seedling trays with washed coconut fibre substrate and kept in darkness at $20-22^{\circ} \mathrm{C}$ and 70 $80 \%$ humidity until radicle emission. Then, the trays were placed in a greenhouse at the University of Almería (Almería, Spain). Seedlings were irrigated only with tap water until the expanded cotyledon stage and then irrigated with nutrient solution until transplant. In a true four-leaf stage, twenty plants per species and treatment were transplanted to a $750 \mathrm{~mL}$ pot with washed coconut fibre substrate and grown under the light treatments for 20 days at 40 plants $* \mathrm{~m}^{-2}$ of density. The culture was carried out in an isolated room used as a growth chamber with dimensions of $3 \mathrm{~m}$ long, $1 \mathrm{~m}$ wide, and $2 \mathrm{~m}$ high, provided with two fans and an air conditioning unit to maintain temperature homogeneity. The photoperiod was a day/night photoperiod of $16 / 8 \mathrm{~h}$ at $28 / 18^{\circ} \mathrm{C}$ day/night temperature and $80 / 85 \%$ relative humidity. Fertigation was replenished if $10 \%$ of the readily available water was consumed (Urrestarazu et al., 2016). The nutrient solution used was recommended by Sonneveld and Straver (1994) for leafy vegetables $\left(1.25 \mathrm{mmol} \cdot \mathrm{L}^{-1} \mathrm{NH}_{4} ; 11.0\right.$ $\mathrm{mmol} \cdot \mathrm{L}^{-1} \mathrm{~K} ; 4.5 \mathrm{mmol} \cdot \mathrm{L}^{-1} \mathrm{Ca} ; 1.0 \mathrm{mmol} \cdot \mathrm{L}^{-1} \mathrm{Mg} ; 19.0 \mathrm{mmol} \cdot \mathrm{L}^{-1}$ $\mathrm{NO}_{3} ; 1.125 \mathrm{mmol} \cdot \mathrm{L}^{-1} \mathrm{SO}_{4} ; 2.0 \mathrm{mmol} \cdot \mathrm{L}^{-1} \mathrm{H}_{2} \mathrm{PO}_{4} ; 40 \mu \mathrm{mol} \cdot \mathrm{L}^{-1} ; 5$ $\mu \mathrm{mol} \cdot \mathrm{L}^{-1} \mathrm{Mn} ; 4 \mu \mathrm{mol} \cdot \mathrm{L}^{-1} \mathrm{Zn} ; 30 \mu \mathrm{mol} \cdot \mathrm{L}^{-1} \mathrm{~B} ; 0.75 \mu \mathrm{mol} \cdot \mathrm{L}^{-1} \mathrm{Cu}$; $\left.0.5 \mu \mathrm{mol} \cdot \mathrm{L}^{-1} \mathrm{Mo}\right)$. The electrical conductivity was adjusted to 2.6 $\mathrm{dS} \cdot \mathrm{m}^{-1}$ following the recommendation of Sonneveld and Straver in 1994.

Two types of LED lamp tubes were used for the light treatment. S1 was the L18 T8 standard white light, Ecotubo120018B, $6500 \mathrm{~K}$, with an electric consumption of $18 \mathrm{~W}$ by Roblan ${ }^{\mathrm{TM}}$ (Toledo, Spain), and S2 was the L18 AP67 spectrum, Valoya L18 spectrum AP67 Milky, $2500 \mathrm{~K}$, also with an electric consumption of $18 \mathrm{~W}$, by Valoya ${ }^{\mathrm{TM}}$ (Helsinki, Finland), specially designed for horticultural growth.

The specific light spectra of S1 and S2 were recorded with a UPRtek MK350S LED meter (Miaoli Country, Taiwan). As shown in Figure 1, S2 showed a decrease in the blue $(450 \mathrm{~nm})$ and green $(540 \mathrm{~nm})$ wavelengths, with a relative intensity value of 0.8 and 0.3 , respectively. Conversely, $\mathrm{S} 1$ spectrum reached a relative intensity value of 1 and 0.54 for the same blue and green specific wavelengths. S2 also had more relative intensity in the red $(660 \mathrm{~nm})$ and far-red region $(740 \mathrm{~nm})$ with a relative intensity value of 1 and 0.2 compared to $\mathrm{S} 1$, which registered values of 0.2 and 0.05 for these same spectral regions (Table 1). Additionally, two intensities were tested, low $(\mathrm{L})$ and high $(\mathrm{H})$ intensity, respectively achieved by 
four and six lamps per square meter. The plant pots were placed on solid base four-level shelves. The lamps were located at the top of each level, $50 \mathrm{~cm}$ from the plants.

The light intensity as photosynthetic photon flux density (PPFD) $\left(\mu \mathrm{mol} \cdot \mathrm{m}^{-2} \cdot \mathrm{s}^{-1}\right)$ and illuminance (lux) were measured with an HD 2302.0 Light Meter (Delta $\mathrm{OHM}^{\mathrm{TM}}$, Veneto, Italy) using an LP 471 PAR probe and LP 471 PHOT quantum radiometric probe, respectively (Table 2). The measurements were made on 9 points for each light condition $50 \mathrm{~cm}$ from the lamps. The intensity was adjusted using lamps with the same energy consumption (18 w) by the number of lamps and the distance to the plants. The differences in the lamps' red and blue spectral relation caused slight variations in the range of light intensity in each treatment (Table 2). So, S1LI and S2LI caused a different illumination for the LI treatments, where S1L1 reached a PPFD of $78.04 \mu \mathrm{mol} \mathrm{m} \mathrm{m}^{-2} \mathrm{~s}^{-1}$, while S2L1 was $62.89 \mu \mathrm{mol} \mathrm{m} \mathrm{m}^{-2} \mathrm{~s}^{-1}$ (Table 2). Both intensities are very low, slightly higher than the light compensation limit so that lettuce may accumulate nitrates in the leaves (Cometti et al., 2011).
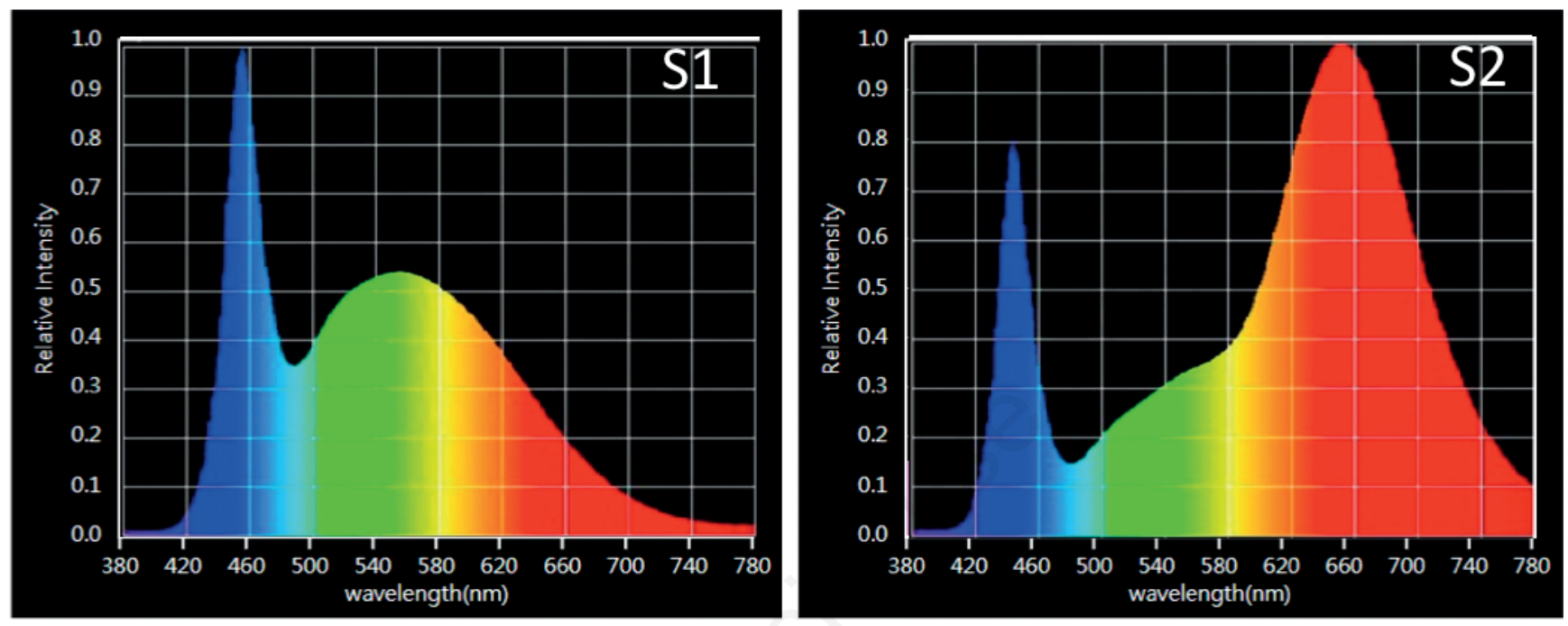

Figure 1. Spectral photon flux from 380 to $780 \mathrm{~nm}$ lighting treatments for L18 T8 model Ecotubo120018B, 6500 K, Roblan ${ }^{\mathrm{TM}}$, which correspond to a standard white light-emitting diode (LED) lamp (S1: Spectrum 1) and L18 AP67 spectrum, model: Valoya L18 spectrum AP67 Milky, $2500 \mathrm{~K}$, Valoya ${ }^{\text {TM }}$ LED specifically designed for agricultural uses (S2: Spectrum 2). Both spectra were recorded with a UPRtek MK350S LED meter (Miaoli CountyTaiwan).

Table 1. Light spectrum percentage of L18 T8 (S1) and L18 AP67 (S2) lamps used on endive and lettuce grown under indoor conditions.

\begin{tabular}{lccc} 
Spectrum & Wavelength $(\mathrm{nm})$ & L18 T8 (S1) (\%)* AP67 (S2) (\%) \\
UV & $380-400$ & 0.50 & 0.53 \\
Blue & $400-500$ & 32.84 & 16.93 \\
\hline Green & $500-600$ & 42.51 & 20.54 \\
Red & $600-700$ & 21.73 & 49.67 \\
\hline Far red & $700-780$ & 2.41 & 12.33 \\
Total & & 100.00 & 100.00 \\
\hline
\end{tabular}

*Values correspond to the relative percentage of the different wavelength ranges in all the spectra for each type of lamp.

Table 2. Light conditions used to grow endive and lettuce plants under indoor conditions. Photosynthetic photon flux density intensity and illuminance for two light spectra combined with two levels of intensities were used as treatments.

\begin{tabular}{lcccc} 
Spectrum & Level intensity & Treatment & Light intensity as PPFD $\left(\mu m_{0} \cdot m^{-2} s^{-1}\right)$ & Illuminance (lux) \\
S1 & LI & S1LI & $78.04 \pm 7.44$ & $3528.8 \pm 297.9$ \\
& HI & S1HI & $102.56 \pm 8.90$ & $4610.8 \pm 351.5$ \\
\hline S2 & LI & S2LI & $62.89 \pm 5.20$ & $2210.9 \pm 183.5$ \\
& HI & S2HI & $100.06 \pm 6.98$ & $2931.9 \pm 249.0$ \\
\hline
\end{tabular}

S1 corresponds to a standard white LED (L18 T8 Roblan ${ }^{\mathrm{TM}}$ ); S2 corresponds to a specific LED spectrum for horticultural crops (L18 EU AP67 Valoya ${ }^{\mathrm{TM}}$ ) at low (LI) and high intensity (HI). Photosynthetic photon flux (PPFD) $\left(\mu \mathrm{mol} \cdot \mathrm{m}^{-2} \cdot \mathrm{s}^{-1}\right)$ and illuminance (lux) were measured with an HD 2302.0 Light Meter (Delta OHM ${ }^{\mathrm{TM}}$, Veneto, Italy). 


\section{Growth parameters}

Three random plants per repetition and three repetitions per treatment were considered for all the measurements $(n=9)$. Border plants were not considered for the analysis. Leaf, root, and total fresh weight (FW) were measured after 20 days from transplant and expressed as grams (g). Dry weight (DW) measurements were obtained after oven-drying until constant weight at $60^{\circ} \mathrm{C}$.

The dry weight percentage (DW\%) was calculated with FW and DW of leaf and root. The number of leaves on the fresh plant was also counted. Next, the chlorophyll content was measured as the soil plant analysis development (SPAD) index with a portable chlorophyll meter (SPAD-502; Minolta, Osaka, Japan). Next, leaf area (LA) was gauged after processing digital images with the Image J program, a free domain program developed by the National Institutes of Health (NIH), version v1.51j8 (Schneider et al., 2012). Finally, each plant's specific leaf area (SLA) was calculated using the following equation and expressed as $\mathrm{cm}^{2} \cdot \mathrm{g}^{-1}$.

$$
S L A=\frac{L A}{\text { Leaf dryweight }}
$$

\section{Extraction of antioxidant compound fraction for meas- urements}

Phenolic compounds were extracted as described by Galieni et al. (2015) with some modifications. About $0.2 \mathrm{~g}$ of freeze-dried leaves powder was suspended in $10 \mathrm{~mL}$ of methanol: water (70:30), the vortex was shaken for $1 \mathrm{~min}$ and placed in an ultrasound bath for $15 \mathrm{~min}$. The mixture was centrifuged at $4^{\circ} \mathrm{C}$ for 15 min at $4180 \mathrm{~g}_{N}$, and the supernatant was filtered through a PVDF membrane with a $0.45 \mu \mathrm{m}$ pore size. The extract was used to evaluate total phenol content (TPC), total flavonoids, and antioxidant activity using the ferric reducing ability of plasma (FRAP) and 2,2diphenyl-1-picrylhydrazyl (DPPH) methods.

\section{Total phenol content}

TPC of the methanol-water fraction was evaluated using the Folin-Ciocalteu reagent following the method described by Ainsworth and Gillespie (2007). $200 \mu \mathrm{L}$ of $10 \%$ Folin-Ciocalteu reagent were added to $100 \mu \mathrm{L}$ of the extract and mixed by the vortex. Then, $800 \mu \mathrm{L}$ of $700 \mathrm{mM} \mathrm{Na}_{2} \mathrm{CO}_{3}$ were added and maintained at room temperature in darkness for $120 \mathrm{~min}$. Finally, the reaction product was read at $765 \mathrm{~nm}$ using a Biochrom multiplate reader (Asys UVM 340, Biochrom, Cambridge, UK). TPC was expressed as milligrams of gallic acid equivalent per $100 \mathrm{~g}$ of fresh weight (mg GAE $100 \mathrm{~g}^{-1} \mathrm{FW}$ ).

\section{Total flavonoid content}

Total flavonoid content was determined with the aluminium chloride as described by Tharasena and Lawan (2014) with modifications. $100 \mu \mathrm{L}$ of $5 \% \mathrm{NaNO}_{2}$ were added to $100 \mu \mathrm{L}$ of the extract, and after $5 \mathrm{~min}, 10 \% \mathrm{AlCl}_{3}$ was added. After standing for $6 \mathrm{~min}$ at room temperature, $670 \mu \mathrm{L}$ of $1 \mathrm{M} \mathrm{NaOH}$ were added. Finally, the reaction absorbance was measured at $510 \mathrm{~nm}$ using a Biochrom multiplate reader. The result was expressed as milligrams of rutin equivalents per $100 \mathrm{~g}$ of fresh weight (mg Rut $\left.\mathrm{Eq} \cdot 100 \mathrm{~g}^{-1} \mathrm{FW}\right)$.

\section{Antioxidant activity assays}

The free radical scavenging activity was measured using DPPH as Gupta and Prakash (2009) described. Briefly, $1 \mathrm{~mL}$ of 0.2 $\mathrm{mM}$ DPPH was added to $250 \mu \mathrm{L}$ of diluted extract. The mixes were vigorously shaken and left to stand for $20 \mathrm{~min}$ at room temperature. Changes in absorbance were measured at $517 \mathrm{~nm}$ every 30 min until stabilisation (after $120 \mathrm{~min}$ ) using a Biochrom multiplate reader. The results were expressed as $\mathrm{mg}$ of Trolox per $100 \mathrm{~g}$ of fresh weight (mg Trolox $100 \mathrm{~g}^{-1} \mathrm{FW}$ ) (Llorach et al., 2008).

FRAP was measured as described by Benzie and Strain in 1996. For the FRAP reagent, $300 \mathrm{mM}$ acetate buffer $(\mathrm{pH} \mathrm{3,6);} 10$ $\mathrm{mM} \mathrm{2,4,6-Tris(2-pyridyl)-s-triazine} \mathrm{(TPTZ)} \mathrm{diluted} \mathrm{in} 40 \mathrm{mM} \mathrm{HCl}$ and $20 \mathrm{mM} \mathrm{FeCl}_{3} \cdot 6 \mathrm{H}_{2} \mathrm{O}$ were mixed in a ratio of $10: 1: 1$ and heated 10 minutes at $37^{\circ} \mathrm{C} .20 \mu \mathrm{L}$ of the diluted sample were added to 600 $\mu \mathrm{L}$ of FRAP reagent. Changes in the absorbance were measured at $593 \mathrm{~nm}$ every $30 \mathrm{~min}$ until stabilisation (after $120 \mathrm{~min}$ ) using a Biochrom multiplate reader. Equivalent antioxidant activity was calculated as the ratio of the linear regression coefficient of the sample with Trolox standard (Merck KGaA, Darmstadt, Germany) (Llorach et al., 2008). The results were expressed as mg of Trolox per $100 \mathrm{~g}$ of fresh weight (mg Trolox $100 \mathrm{~g}^{-1} \mathrm{FW}$ ).

\section{Experimental design and statistical analysis}

A randomized complete block design was implemented. Five plants per block and three blocks were analysed for each treatment and species. The statistical analysis was performed using InfoStat, a statistics software developed by Córdoba National University, Argentina (Di Rienzo et al., 2017). Recorded data were subjected to an analysis of variance (multi-factor ANOVA). Mean differences were considered statistically significant when $\mathrm{P}<0.05$ and were detected using Fisher's least significant difference (LSD) test.

\section{Results and discussion}

\section{Effect of light quality on growth parameters}

Growth parameters of the endive and lettuce grown under white light (S1) and AP67 (S2) spectrum at LI and HI intensities were evaluated. Figures 2 and 3 show side (A) and aerial (B) views of the effect of light treatments on the shape and size of endive and lettuce plants, respectively. In endive, there were no significant differences between the growth parameters in S1LI and S2LI, showing no significant differences between the two spectra, despite the differences in light intensity and illuminance of these two treatments. For endive and lettuce, the most significant growth and development were reached using the $\mathrm{S} 2$ and $\mathrm{HI}$ combination. The difference in leaf area (LA) was noted when S1 and S2 were compared. Also, significant differences between LI and HI were found for LA values of endive and lettuce (Tables 3 and 4). These results confirm that these species responded to these spectra enriched by a proportion of red rather than blue light. Similarly, Tosti et al. (2018) found bigger lettuces under a high proportion of red light. Colonna et al. (2015) and Urrestarazu et al. (2016) mentioned that high intensity enhanced the LA values of several horticultural crops under these spectra.

For endive, LA, root FW, and DW were significantly affected by spectrum and light intensity separately and showed higher values at S2 and HI conditions. On the other hand, the SPAD index and root DW\% were not significantly affected by spectrum or intensity (Table 3).

There was an interaction between spectrum and intensity for leaf and total FW and DW parameters. Also, for leaf DW\%, leaf number, and SLA, an interaction was found between the factors studied. Leaf FW showed a $114 \%$ increase when comparing S2HI and S1LI, increasing from 11.70 to $25.08 \mathrm{~g}$. S2HI also showed an 

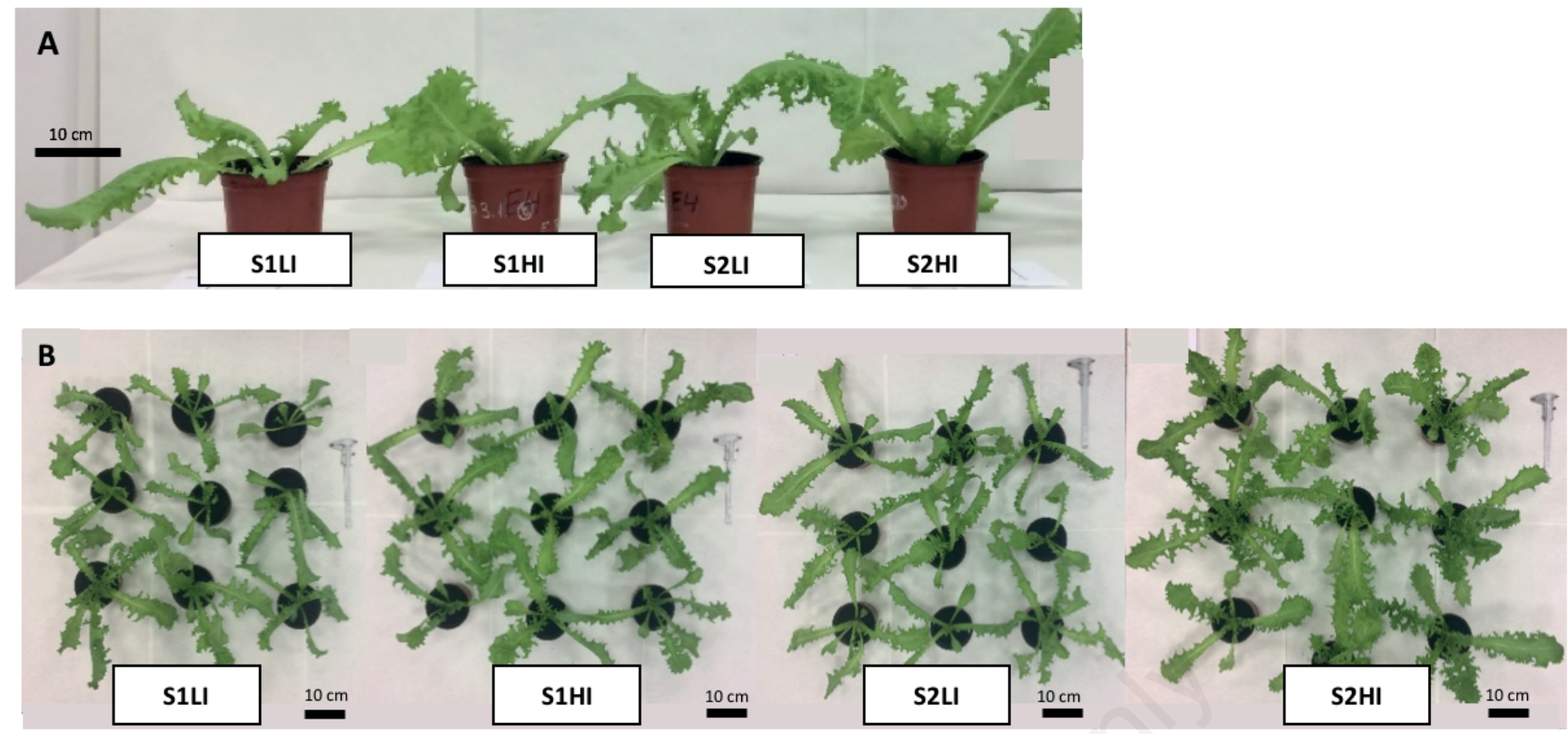

Figure 2. Effect on shape and size of endive growing under two LED spectra and intensities. A) Side view of one plant per treatment; B) aerial view of nine plants per treatment. S1, spectrum 1 (white light); S2, spectrum 2 (AP67L); LI, low intensity; HI, high intensity.
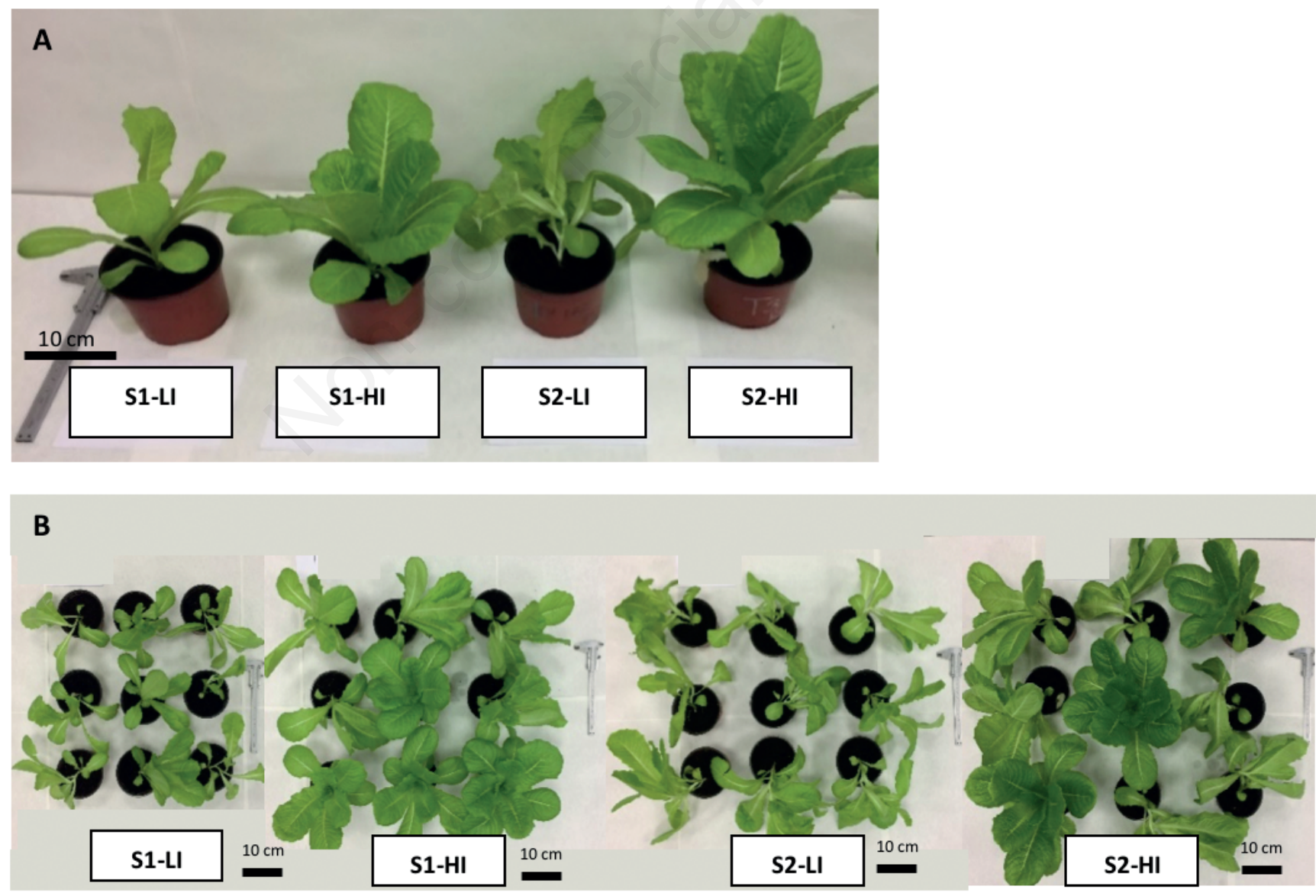

Figure 3. Effect on shape and size of lettuce growing under two LED spectra and intensities. A) Side view of one plant per treatment; B) aerial view of nine plants per treatment. S1, spectrum 1 (white light); S2, spectrum 2 (AP67L); LI, low intensity; HI, high intensity. 
increase in leaf DW, in this case of $132 \%$ compared to S1LI. Additionally, when total FW and DW were evaluated; the values obtained in the S2HI treatment were higher than S1L1, S1HI and S2LI. Furthermore, leaf DW\% was higher in S2HI than S1LI and S2LI. Finally, leaf number also showed an increase in S2HI compared to S1LI, S1HI, and S2LI. On the other hand, SLA reached the highest value of $543.06 \mathrm{~cm}^{2} \cdot \mathrm{g}^{-1}$ DW under S2LI (treatment with lower light intensity and illuminance) and presented the lowest value $\left(409.40 \mathrm{~cm}^{2} \cdot \mathrm{g}^{-1}\right)$ at S2HI (Table 3).

For lettuce, leaf, root, and total FW, root DW, leaf number, and LA were significantly affected by spectrum and intensity separately, showing the highest values under S2 and HI levels. On the other hand, SLA was also significantly affected by spectrum and intensity but showed the lowest values at S2 and HI levels. The SPAD index was only affected by intensity, showing a $21 \%$ increase when HI was compared to LI. Conversely, leaf DW\% values were not affected by spectrum or intensity. Finally, a significant interaction was found for leaf and total DW and root DW\% between spectrum and intensity. Leaf DW had a $468 \%$ increase between S2HI and S1LI, and total DW also reached the highest value in S2HI compared to S1LI. The highest values for root DW\% were found in the S2LI treatment and the lowest in the S1HI treatment (Table 4). The greater DW\% under S2LI with respect to S1LI must be for the spectra since S2LI presents less light intensity than S1LI.

S2 had a significantly increased effect on several growth parameters for both species compared to S1. Although the illuminance and PPFD were higher in S1, S2 had better growth results for both species. These data agreed with those reported by Urrestarazu et al. (2016) for lettuce, peppers, and tomatoes due to the highest photosynthetic responses reached by S2 (McCree, 1972).

This significant increase in growth parameters for endive and lettuce plants in Tables 3 and 4 may be due to the spectrum composition, precisely, because of the increase in red and far-red wavelengths present in S2 compared to the S1 spectrum (Figure 1).

In a previous work, Urrestarazu et al. (2016) mentioned that changes in the light spectrum between 580 and $710 \mathrm{~nm}$ might explain its improved results over white light. In the same way, the results obtained in this study also confirm previous studies, which have reported that the red spectrum induced plant growth by increasing fresh and dry weights and leaf area in different types of lettuce (Yorio et al., 2001; Johkan et al., 2010; Son and Oh, 2013;

Table 3. Effect of two spectral compositions and two light intensities on endive growth parameters.

\begin{tabular}{|c|c|c|c|c|c|c|c|c|c|c|c|c|c|}
\hline \multirow[b]{2}{*}{ Factor } & \multirow[b]{2}{*}{ Level } & \multicolumn{3}{|c|}{ FW (g plant $\left.{ }^{-1}\right)$} & \multicolumn{3}{|c|}{ DW (g plant $\left.{ }^{-1}\right)$} & \multicolumn{2}{|c|}{ DW\% } & \multirow{2}{*}{$\begin{array}{l}\text { Leaf } \mathrm{N}^{\circ} \\
\text { plan }^{t-1}\end{array}$} & \multirow{2}{*}{$\begin{array}{l}\text { SPAD } \\
\text { index }\end{array}$} & \multirow{2}{*}{$\begin{array}{c}\text { LA } \\
\left(\mathrm{cm}^{2} \cdot p l a n^{t-1}\right)\end{array}$} & \multirow{2}{*}{$\begin{array}{c}\text { SLA } \\
\left(\mathrm{cm}^{2} \cdot \mathrm{g}^{-1} \mathrm{DW}\right)\end{array}$} \\
\hline & & Leaf & Root & Total & Leaf & Root & Total & Leaf & Root & & & & \\
\hline \multirow[t]{2}{*}{ Spectrum (S) } & S1 & $13.30^{\mathrm{b}}$ & $5.93^{b}$ & $19.23^{b}$ & $0.72^{b}$ & $0.41^{b}$ & $1.13^{b}$ & 5.18 & 7.07 & $5.67^{\mathrm{b}}$ & 24.22 & $342.13^{b}$ & 495.86 \\
\hline & S2 & $19.85^{\mathrm{a}}$ & $9.11^{\mathrm{a}}$ & $28.96^{\mathrm{a}}$ & $1.09^{a}$ & $0.63^{\mathrm{a}}$ & $1.72^{\mathrm{a}}$ & 5.21 & 6.90 & $7.06^{\mathrm{a}}$ & 26.07 & $485.48^{\mathrm{a}}$ & 476.23 \\
\hline \multirow[t]{2}{*}{ Intensity (I) } & $\mathrm{LI}$ & $13.16^{\mathrm{b}}$ & $5.93^{b}$ & $19.08^{b}$ & $0.68^{b}$ & $0.42^{b}$ & $1.10^{\mathrm{b}}$ & $4.96^{\mathrm{b}}$ & 7.16 & 6.11 & 24.37 & $348.91^{b}$ & $527.12^{\mathrm{a}}$ \\
\hline & $\mathrm{HI}$ & $19.99^{\mathrm{a}}$ & $9.11^{\mathrm{a}}$ & $29.11^{\mathrm{a}}$ & $1.13^{\mathrm{a}}$ & $0.62^{\mathrm{a}}$ & $1.75^{\mathrm{a}}$ & $5.44^{\mathrm{a}}$ & 6.81 & 6.61 & 25.91 & $478.70^{\mathrm{a}}$ & $444.97^{b}$ \\
\hline \multirow[t]{4}{*}{ S.I } & SILI & $11.70^{b}$ & 5.19 & $16.89^{b}$ & $0.62^{b}$ & 0.38 & $1.00^{b}$ & $5.06^{b c}$ & 7.43 & $6.00^{\mathrm{b}}$ & 23.28 & 303.93 & $511.19^{a b}$ \\
\hline & S1HI & $14.90^{\mathrm{b}}$ & 6.67 & $21.57^{\mathrm{b}}$ & $0.81^{b}$ & 0.45 & $1.27^{\mathrm{b}}$ & $5.31^{\mathrm{ab}}$ & 6.71 & $5.33^{b}$ & 25.16 & 380.33 & $480.53^{b}$ \\
\hline & S2LI & $14.61^{\mathrm{b}}$ & 6.67 & $21.28^{b}$ & $0.73^{b}$ & 0.46 & $1.19^{\mathrm{b}}$ & $4.85^{c}$ & 6.89 & $6.22^{b}$ & 25.47 & 393.89 & $543.06^{\mathrm{a}}$ \\
\hline & $\mathrm{S} 2 \mathrm{HI}$ & $25.08^{\mathrm{a}}$ & 11.56 & $36.64^{\mathrm{a}}$ & $1.44^{\mathrm{a}}$ & 0.80 & $2.24^{\mathrm{a}}$ & $5.57^{\mathrm{a}}$ & 6.91 & $7.89^{\mathrm{a}}$ & 26.67 & 577.08 & $409.40^{c}$ \\
\hline S & Pvalue & 0.0007 & 0.0026 & 0.0008 & 0.0016 & 0.0049 & 0.0019 & 0.7586 & 0.6515 & 0.0056 & 0.0509 & 0.0011 & 0.2218 \\
\hline I & Pvalue & 0.0004 & 0.0026 & 0.0006 & 0.0002 & 0.0062 & 0.0006 & 0.0001 & 0.3451 & 0.2909 & 0.1010 & 0.0026 & $<0.0001$ \\
\hline S.I & Pvalue & 0.0431 & 0.0887 & 0.0487 & 0.0229 & 0.0673 & 0.0299 & 0.0338 & 0.3259 & 0.0177 & 0.7121 & 0.1876 & 0.0027 \\
\hline
\end{tabular}

FW, fresh weight; DW, dry weight; SPAD index, soil plant analysis development index; LA, leaf area; SLA, specific leaf area; S1, spectrum 1, standard white LED (L18 T8 Roblan ${ }^{\text {TM}) ; ~ S 2, ~ s p e c t r u m ~ 2, ~ s p e c i f i c ~ h o r t i c u l t u r a l ~}$ spectrum (L18 EU AP67 Valoya ${ }^{\mathrm{TM}}$ ); LI, low intensity; HI, high intensity. S.I interaction. Values are means of $\mathrm{n}=9$ for the interaction. ${ }^{\mathrm{a}-\mathrm{c}}$ Different letters correspond to statistical differences determined by Fisher's LSD test $(\mathrm{P}<0.05)$.

Table 4. Effect of two spectral compositions and two light intensities on lettuce growth parameters.

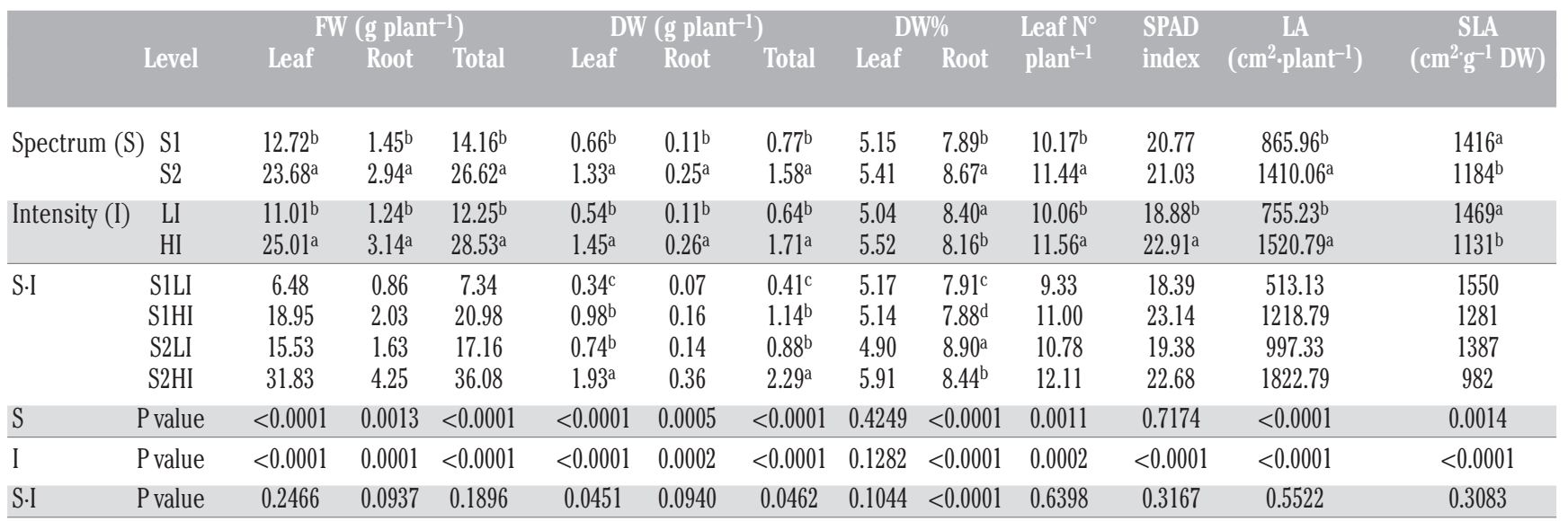

FW, fresh weight; DW, dry weight; SPAD index, soil plant analysis development index; LA, leaf area; SLA, specific leaf area; S1, spectrum 1, standard white LED (L18 T8 Roblan ${ }^{\text {TM}}$ ); S2, spectrum 2, specific horticultural spectrum (L18 EU AP67 Valoya $^{\mathrm{TM}}$ ); LI, low intensity; HI, high intensity. S.I interaction. Values are means of $\mathrm{n}=9$ for the interaction. ${ }^{\text {a-d }}$ Different letters correspond to statistical differences determined by Fisher's LSD test $(\mathrm{P}<0.05)$. 
2015; Tosti et al., 2018). Similarly, Hasan et al. (2017) found that under controlled environmental conditions, red LED lighting acted as the main light source for growing vegetables and enhancing yield and dry weight, explaining the increase in growth parameters by using S2. These results were also consistent with previous studies reported by Stenbaek and Jensen (2010), Son and Oh (2013), and Wang et al. (2016), who described mixed blue and red LEDs, present in S2, as enhancing the growth of various vegetables by increasing the photosynthetic rate in leaves. This could be because the absorption peaks of photosynthetic pigments, specifically chlorophyll $a$ and $b$, effectively absorb both red $(600-700 \mathrm{~nm})$ and blue (400-500 nm) wavelengths of light (Son and Oh, 2015; Murakami and Matsuda, 2016). Tosti et al. (2018) also found that lettuces treated with a greater proportion of red light over blue increased leaf area and accumulation of biomass as the red wavelength allow higher absorption of radiation, the efficiency of the radiation use, and its conversion into biomass. However, Bartucca et al. (2020) found that a higher proportion of blue over red light produced a higher yield of einkorn wheatgrass related to a more remarkable synthesis of photosynthetic pigments.

The SPAD index is related to chlorophyll content, and its increase could be responsible for elevated fresh and dry weights in plants. This study demonstrated that the light intensity significantly increased the SPAD index of lettuce. Similarly, Yao et al. (2017) showed that an increase in light intensity on the red light wavelength generated high total chlorophyll content and photosynthetic efficiency in rape seedlings cultivated under blue and red LEDs.

SLA exhibited a significant reduction in S2 and HI compared to $\mathrm{S} 1$ and LI for lettuce, indicating that leaves in the first combination were thicker, consistent with the highest leaf dry weight per unit of leaf area. These results agree with those found by Yao et al. (2017), who reported that rape leaves under high illumination were denser and more compact, with a thicker and tidier palisade and spongy tissues with well-developed chloroplasts. Therefore, high intensities of about $100 \mu \mathrm{mol} \cdot \mathrm{m}^{-2} \cdot \mathrm{s}^{-1}$ were better than low intensities of $70 \mu \mathrm{mol} \mathrm{m} \mathrm{m}^{-2} \cdot \mathrm{s}^{-1}$.

On the other hand, Yao et al. (2017) reported that leaf morphology showed plasticity, and the photosynthetic characteristics and structure of leaves varied markedly under different light intensities. Low light conditions can reduce DW produce thinner leaves with a smaller leaf area, whereas extremely high light intensity reduces the leaf area as a protective mechanism against oxidative damage to leaf tissues (Farquhar and Sharkey, 1982). Only under an appropriate light intensity, plants can fully self-regulate to absorb and transform light energy (Yao et al., 2017).

\section{Effect of light quality on antioxidant compounds}

TPC, TFC, and AA by DPPH for endive were significantly affected by light intensity but not by spectrum (Table 5). At the HI level, a $34.9 \%$ increase for TPC, 39.8\% for TFC, and $50.7 \%$ for AA by DPPH were found compared to LI. Only AA by FRAP was affected by light intensity and spectrum separately. S2 showed a $21.3 \%$ decrease in AA by FRAP compared to S1. Conversely, HI showed a $42.4 \%$ increase compared to the LI level.

For lettuce, there was an interaction between light spectrum and intensity for AA measured by DPPH, showing the highest values in plants grown under S2HI. The greater AA in S2LI than S1LI must be due to the spectra because S2LI presents less light intensity than S1LI. On the other hand, TPC, TFC, and AA by FRAP were affected only by light intensity (Table 6). The HI level showed a $22.7 \%$ increase for TPC, $43.2 \%$ for TFC, and $40.2 \%$ for AA measured by FRAP compared to LI.

These results were according to the spectrum characteristics (Figure 1: S1 and S2). Both spectra presented blue light (400 to $500 \mathrm{~nm}$ ), and this wavelength range may be responsible for enhanced phytochemical contents (Ebisawa et al., 2008; Son and Oh 2013; 2015). Benincasa et al. (2020) also found an increase in polyphenols, tannins, flavonoids, and phenolic acid contents of einkorn sprouts under blue light. Ebisawa et al. (2008) showed in lettuce that in the presence of blue light, the synthesis of flavonol synthase (FLS), the enzyme responsible for converting dihydroquercetin to quercetin, was increased. By contrast, Son and Oh (2015) showed that TPC and AA increased when blue light was used on lettuce cultures. In our study, S2 had about $20 \%$ less blue light than S1; however, this reduced blue light was not enough to affect the synthesis of phenols and flavonoids, and no significant differences were found between spectra for these measurements.

Alternatively, plants grown under high light intensity could have higher photon absorption, which could generate a greater

Table 5. Effect of two spectral compositions and two light intensities on total phenol content, total flavonoid content, and antioxidant activity by 2,2-diphenyl-1-picrylhydrazyl and ferric reducing ability of plasma in endive.

\begin{tabular}{|c|c|c|c|c|c|}
\hline & & & & Antioxidant & 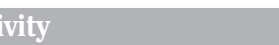 \\
\hline & Level & $\begin{array}{c}\text { TPC } \\
\text { mg GAE. } 100 \mathrm{~g}^{-1} \mathrm{FW}\end{array}$ & $\begin{array}{c}\text { TFC } \\
\text { mg RutEq.100g-1 FW }\end{array}$ & $\begin{array}{l}\text { DPPH } \\
\text { mg Trolox } 100 \mathrm{~g}^{-1} \mathrm{FW}\end{array}$ & $\begin{array}{l}\text { FRAP } \\
\text { mg Trolox } 100 \mathrm{~g}^{-1} \mathrm{FW}\end{array}$ \\
\hline Spectrum (S) & $\begin{array}{l}\text { S1 } \\
\text { S2 }\end{array}$ & $\begin{array}{l}91.25 \\
77.49\end{array}$ & $\begin{array}{l}216.52 \\
197.83\end{array}$ & $\begin{array}{l}347.18 \\
290.38\end{array}$ & $\begin{array}{l}236.49^{\mathrm{a}} \\
186.12^{\mathrm{b}}\end{array}$ \\
\hline Intensity (I) & $\begin{array}{l}\mathrm{LI} \\
\mathrm{HI}\end{array}$ & $\begin{array}{l}71.84^{\mathrm{b}} \\
96.90^{\mathrm{a}}\end{array}$ & $\begin{array}{l}172.80^{\mathrm{b}} \\
241.55^{\mathrm{a}}\end{array}$ & $\begin{array}{l}254.32^{\mathrm{b}} \\
383.24^{\mathrm{a}}\end{array}$ & $\begin{array}{l}174.38^{\mathrm{b}} \\
248.23^{\mathrm{a}}\end{array}$ \\
\hline S.I & $\begin{array}{l}\text { S1LI } \\
\text { S1HI } \\
\text { S2LI } \\
\text { S2HI }\end{array}$ & $\begin{array}{c}81.31 \\
101.20 \\
62.37 \\
92.60\end{array}$ & $\begin{array}{l}198.51 \\
234.52 \\
147.09 \\
248.58\end{array}$ & $\begin{array}{l}306.62 \\
387.74 \\
202.02 \\
378.74\end{array}$ & $\begin{array}{l}211.55 \\
261.44 \\
137.21 \\
235.03\end{array}$ \\
\hline S & P value & 0.0658 & 0.3220 & 0.0849 & 0.0180 \\
\hline I & Pvalue & 0.0064 & 0.0074 & 0.0034 & 0.0032 \\
\hline S.I & P value & 0.4315 & 0.1075 & 0.1335 & 0.1756 \\
\hline
\end{tabular}

TPC, total phenol content; TFC, total flavonoid content; DPPH, 2,2-diphenyl-1-picrylhydrazyl; FRAP, ferric reducing ability of plasma; GAE, gallic acid equivalent; FW, fresh weight; S1, spectrum 1, standard white LED (L18 T8 Roblan ${ }^{\mathrm{TM}}$ ); S2, spectrum 2, specific horticultural spectrum (L18 EU AP67 Valoya ${ }^{\mathrm{TM}}$; LI, low intensity; HI, high intensity. S.I interaction. Values for the interaction are means of $\mathrm{n}=3$. ${ }^{\mathrm{a}-\mathrm{b}} \mathrm{Different}$ letters correspond to statistical differences determined by Fisher's LSD test $(\mathrm{P}<0.05)$. 
Table 6. Effect of two spectral compositions and two light intensities on total phenol content, total flavonoid content, and antioxidant activity by 2,2-diphenyl-1-picrylhydrazyl and ferric reducing ability of plasma in lettuce.

\begin{tabular}{|c|c|c|c|c|c|}
\hline & & & & Antioxide & It activity \\
\hline & Level & $\begin{array}{c}\text { TPC } \\
\text { mg GAE. } 100 \mathrm{~g}^{-1} \mathrm{FW}\end{array}$ & $\begin{array}{c}\text { TFC } \\
\text { mg RutEq } \cdot 100 \mathrm{~g}^{-1} \mathrm{FW}\end{array}$ & $\begin{array}{c}\text { DPPH } \\
\text { mg Trolox } 100 \mathrm{~g}^{-1} \mathrm{FW}\end{array}$ & $\begin{array}{c}\text { FRAP } \\
\text { mg Trolox } 100 \mathrm{~g}^{-1} \mathrm{FW}\end{array}$ \\
\hline Spectrum (S) & S1 & 147.54 & 381.10 & $662.52^{\mathrm{b}}$ & 411.06 \\
\hline & S2 & 164.75 & 434.00 & $976.14^{\mathrm{a}}$ & 447.07 \\
\hline Intensity (I) & $\mathrm{LI}$ & $140.18^{b}$ & $335.09^{b}$ & $597.52^{\mathrm{b}}$ & $357.24^{b}$ \\
\hline & HI & $172.11^{\mathrm{a}}$ & $480.00^{\mathrm{a}}$ & $1041.14^{\mathrm{a}}$ & $500.89^{a}$ \\
\hline S.I & S1LI & 138.39 & 334.67 & $591.68^{b}$ & 359.03 \\
\hline & S1HI & 156.70 & 427.52 & $733.35^{b}$ & 463.09 \\
\hline & S2LI & 141.98 & 335.51 & $603.35^{\mathrm{b}}$ & 355.45 \\
\hline & S2HI & 187.51 & 532.48 & $1348.92^{\mathrm{a}}$ & 538.69 \\
\hline S & Pvalue & 0.1088 & 0.1122 & 0.0006 & 0.3911 \\
\hline I & Pvalue & 0.0129 & 0.0022 & 0.0001 & 0.0103 \\
\hline S.I & Pvalue & 0.1868 & 0.1169 & 0.0008 & 0.3488 \\
\hline
\end{tabular}

TPC, total phenol content; TFC, total flavonoid content; DPPH, 2,2-diphenyl-1-picrylhydrazyl; FRAP, ferric reducing ability of plasma; GAE, gallic acid equivalent; FW, fresh weight; S1, spectrum 1, standard white LED (L18 T8 Roblan ${ }^{\mathrm{TM}}$ ); S2, spectrum 2, specific horticultural spectrum (L18 EU AP67 Valoya ${ }^{\mathrm{TM}}$; LI, low intensity; HI, high intensity. S.I interaction. Values for the interaction are means of $\mathrm{n}=3{ }^{\mathrm{a}}{ }^{\mathrm{a}} \mathrm{D}$ Different letters correspond to statistical differences determined by Fisher's LSD test $(\mathrm{P}<0.05)$.

amount of reducing power, which can be subsequently consumed in the Calvin cycle (Bowyer and Leeggood, 1997). The excess energy could cause photoinhibition, generating reactive oxygen species (ROS) if not effectively removed (Bowyer and Leegood, 1997; Edreva, 2005). Some authors have reported that to reduce and/or scavenge ROS formed under high light intensity, vegetables such as different types of lettuce increase the synthesis of total phenol and flavonoid content species (Edreva, 2005; Oh et al., 2009). Therefore, although the differences between LI and HI have not been very large, they have been sufficient to increase the content of phenolic compounds and antioxidant activity.

In agreement with the results shown in this study for endive and lettuce plants, the increase in phenolic and flavonoid contents under high light intensity may be related to an increase in the expression of phenylalanine ammonia-lyase, the gateway enzyme in the phenylpropanoid pathway, and chalcone synthase, the key enzyme involved in flavonoid biosynthesis (Leyva et al., 1995; Oh et al., 2009). Furthermore, Ebisawa et al. (2008), Liu et al. (2016), Pérez-López et al. (2018), and Craver et al. (2017) also reported that light intensity had a significant influence on flavonoid biosynthesis. Finally, like in this study, Pérez-López et al. (2013) reported that lettuce showed improved antioxidant activity due to a highintensity light treatment. Crozier et al. (2006) explained this phenomenon as being due to an increase in sugar availability generated by high photosynthetic rates under high-intensity light and the close link between the phenylpropanoid pathway and carbohydrate metabolism via the shikimate pathway.

\section{Conclusions}

The results demonstrate that the light spectrum with an increased proportion of red and far-red wavelengths (S2) was beneficial for growing endive and lettuce plants by increasing fresh and dry weights compared to the white light spectrum (S1). Also, $\mathrm{S} 2$ increased the number of leaves and leaf areas for both species. However, the studied spectra (S1 and S2) did not modify the antioxidant compound contents for either species.

Furthermore, both spectra increased growth parameters and TPC for endive and lettuce when a higher light intensity (about 100 $\mu \mathrm{mol} \cdot \mathrm{m}^{-2} \mathrm{~s}^{-1}$ of photons) was applied. The combination of S2 and HI levels used in this work could be considered optimal for endive and lettuce plants due to the high growth indicators achieved. Therefore, manipulating the spectral composition and intensity of the light proved to be a powerful tool for stimulating growth and secondary plant metabolite accumulation, particularly in leafy vegetables cultivated in intensive management systems or indoor conditions.

\section{References}

Ainsworth EA, Gillespie KM, 2007. Estimation of total phenolic content and other oxidation substrates in plant tissues using Folin-Ciocalteu reagent. Nat. Protoc. 2:875-7.

Bartucca ML, Guiducci M, Falcinelli B, Del Buono D, Benincasa P, 2020. Blue:Red LED light proportion affects vegetative parameters, pigment content, and oxidative status of einkorn (Triticum monococcum L. sp.pl. monococcum) wheatgrass. J Agr Food Chem. 68:8757-63.

Benincasa P, Tosti G, Farneselli M, Maranghi S, Bravi E, Marconi O, Falcinelli B, Guiducci M, 2020. Phenolic content and antioxidant activity of einkorn and emmer sprouts and wheatgrass obtained under different radiation wavelengths. Ann. Agric. Sci. 65:68-76.

Benzie IF, Strain JJ, 1996. The ferric reducing ability of plasma (FRAP) as a measure of 'antioxidant power': The FRAP Assay. Anal. Biochem. 239:70-6.

Bowyer JB, Leeggood RC, 1997. Phtosynthesis. In: P.M. Dey, J.B. Harborne (Eds.), Plant biochemistry. Academic Press Ltd., San Diego, CA, USA, pp. 49-110.

Chen X-L, Li Y-L, Wang L-C, Guo W-Z, 2021. Red and blue wavelengths affect the morphology, energy use efficiency and nutritional content of lettuce (Lactuca sativa L.). Sci. Rep. 11:8374

Choi HG, Moon BY, Kang NJ, 2015. Effects of LED light on the production of strawberry during cultivation in a plastic greenhouse and in a growth chamber. Sci. Hortic. 189:22-31.

Colonna E, Rouphael Y, Barbieri G, De Pascale S, 2015. Nutritional quality of ten leafy vegetables harvested at two 
light intensities. Food Chem. 199:702-10.

Cometti, N.N., Martins MQ, Bremenkamp CA, Nunes JA, 2011. Nitrate concentration in lettuce leaves depending on photosynthetic photon flux and nitrate concentration in the nutrient solution. Hortic. Bras. 29:548-53.

Craver JK, Gerovac JR, Lopez RG, Kopsell DA, 2017. Light quality from sole-source light-emitting diodes impact phytochemical concentrations within Brassica microgreens. J. Am. Soc. Hortic. Sci. 142:3-12.

Crozier A, Jaganath IB, Clifford MN, 2006. Phenols, polyphenols and tannins: an overview. In: A. Crozier, M.N. Clifford, H. Ashihara (Eds.), Plant secondary metabolites: occurrence, structure, and role in the human diet. Blackwell Publishing, Oxford, UK, pp. 1-24.

Di Rienzo JA, Casanoves F, Balzarini MG, Gonzalez L, Tablada M, Robledo CW, 2017. InfoStat versión. Grupo InfoStat, FCA, Universidad Nacional de Córdoba, Argentina.

Ebisawa M, Shoiji K, Kato M, Shimomura K, Goto F, Yoshihara T, 2008. Supplementary ultraviolet radiation B together with blue light at night increased quercetin content and flavonol synthase gene expression in leaf lettuce (Lactuca sativa L.). Envirom. Control Biol. 46:1-11.

Edreva A, 2005. The importance of non-photosynthetic pigments and cinnamic acid derivatives in photoprotection. Agric. Ecosyst. Environ. 106:135-46.

Fan XX, Xu ZG, Liu XY, Tang CM, Wang LW, Han XL, 2013. Effects of light intensity on the growth and leaf development of young tomato plants grown under a combination of red and blue light. Sci. Hort. 153:50-5.

Farquhar GD, Sharkey TD, 1982. Stomatal conductance and photosynthesis. Annu. Rev. Plant Physiol. 33:317-45.

FAO (Food and Agriculture Organization of the United Nations), 2020. FAOSTAT, Crops. Metadata last update 29-07-2020. Last actualization: 22/12/2020. Accessed: 17/02/2021.

Galieni A, Di Mattia C, De Gregorio M, Speca S, Mastrocola D, Pisante M, Stagnari F, 2015. Effects of nutrient deficiency and abiotic environmental stresses on yield, phenolic compounds, and antiradical activity in lettuce (Lactuca sativa L.). Sci. Hort. 187:93-101.

Gupta S, Prakash J, 2009. Studies on Indian green leafy vegetables for their antioxidant Activity. Plant Foods Hum. Nutr. 64:3945.

Hao X, Zheng JM, Little C, Khosla S, 2012. LED inter-lighting in year-round greenhouse mini-cucumber production. Acta Hortic. 956:335-40.

Hasan M, Bashir T, Ghosh R, Lee SK, Bae H, 2017. An overview of LEDs' effects on the production of bioactive compounds and crop quality. Molecules 22:1420.

Huché-Thélier L, Crespel L, Le Gourrierec J, Morel P, Sakr S, Leduc N, 2016. Light signaling and plant responses to blue and UV radiations-perspectives for applications in horticulture. Environ. Exper. Bot. 121:22-38.

Johkan M, Shoji K, Goto F, Hashida S, Yoshihara T, 2010. Blue light-emitting diode light irradiation of seedlings improves seedling quality and growth after transplanting in red leaf lettuce. HortSci. 45:1809-14.

Kozai T, Niu G, 2016. Chapter 1-Introduction. In: T. Kozai, G. Niu, M. Takagaki (Eds.), Plant factory: An indoor vertical farming system for efficient quality food production. Elsevier, Boston, MA, USA pp. 3-5.

Leyva A, Jarillo JA, Salinas J, Martinezzapate, JM, 1995. Low temperature induces the accumulation of phenylalanine ammonia lyase and chalcone synthase messenger RNAs of
Arabidopsis thaliana in a light dependent manner. Plat Physiol. 108:39-46.

Liu XY, Xu ZG, Chang TT, Guo SR, 2010. Growth and photosynthesis of cherry tomato seedling exposed to different low light of LED light quality. Acta Bot. Boreal-Occid. Sin. 30:645-51.

Liu Y, Qian C, Ding S, Shang X, Yang W. Fang S, 2016. Effect of light regime and provenance on leaf characteristics, growth, and flavonoid accumulation in Cyclocarya paliurus (Batal) Iljinskaja coppices. Bot. Stud. 57:28.

Llorach R, Martínez-Sánchez A, Tomás-Barberán FA, Gil MI, Ferreres F, 2008. Characterization of polyphenols and antioxidant properties of five lettuce varieties and escarole. Food Chem. 108:1028-38.

Murakami K, Matsuda R, 2016. Optical and physiological properties of a leaf. In: T. Kozai, K. Fujiwara, E. Runkle (Eds.), LED lighting for urban agriculture. Springer, Singapore, pp. 113-23.

McCree KJ, 1972. The action spectrum, absorbance, and quantum yield of photosynthesis in crop plants. Agr. Meteorol. 9:191216.

Oh MM, Carey EE, Rajashekar CB, 2009. Environmental stresses induce health-promoting phytochemicals in lettuce. Plant Physiol. Biochem. 47:578-83.

Pérez-López U, Miranda-Apodaca J, Muñóz-Rueda A, MenaPetite A, 2013. Lettuce production and antioxidant capacity are differentially modified by salt stress and light intensity under ambient and elevated $\mathrm{CO}_{2}$. J. Plant Physiol. 170:1517-25.

Pérez-López U, Sgherri C, Miranda-Apodaca J, Micaelli F, Lacuesta M, Mena-Petite A, Quartacci MF, Muñóz-Rueda A, 2018. Concentration of phenolic compounds is increased in lettuce grown under high light intensity and elevated $\mathrm{CO}_{2}$. Plant Physiol. Biochem. 123:233-41.

Sabzalian MR, Heydarizadeh P, Zahedi M, Boroomand A, Agharokh M, Sahba MR, Schoefs B, 2014. High performance of vegetables, flowers, and medicinal plants in a red-blue LED incubator for indoor plant production. Agron. Sustain. Dev. 34:879-86.

Schneider CA, Rasband WS, Eliceiri KW, 2012. NIH Image to ImageJ: 25 years of image analysis. Nature Methods 9:671-5.

Shirke PA, Pathre UV, 2003. Diurnal and seasonal changes in photosynthesis and photosystem 2 photochemical efficiency in Prosopis juliflora leaves subjected to natural environmental stress. Photosynthetica. 41:83-9.

Snowden MC, Cope KR, Bugbee B, 2016. Sensitivity of seven diverse species to blue and green light: interactions with photon flux. PLoS One 11:e0163121.

Son KH, Oh MM, 2013. Leaf shape, growth, and antioxidant phenolic compounds of two lettuce cultivars grown under various combinations of blue and red light-emitting diodes. HortSci. 48:988-95

Son KH, Oh MM, 2015. Growth, photosynthetic and antioxidant parameters of two lettuce cultivars as affected by red, green, and blue light-emitting diode. Hortic. Environ. Biotechnol. 56:639-53.

Sonneveld C, Straver N, 1994. Voedingsoplossingen voor groenten en bloemen geteeld in water of substraten [Nutrient solutions for vegetables and flower grown in water or substrates]. 10th ed. Proefstation voor Tuinbouw onder Glas, Naaldwijk, Netherlands.

Stenbaek A, Jensen PE, 2010. Redox regulation of chlorophyll biosynthesis. Phytochemistry. 71:853-9.

Tharasena B, Lawan S, 2014. Phenolics, flavonoids and antioxidant activity of vegetables as thai side dish. APCBEE Procedia 8:99-104. 
Tosti G, Benincasa P, Cortona R, Falcinelli B, Farneselli M, Guiducci M, Onofri A, Pannacci E, Tei F, Giulietti M, 2018. Growing lettuce under multispectral light-emitting diodes lamps with adjustable light intensity. Ital. J. Agron. 13:57-62.

Urrestarazu M, Nájera C, Gea M, 2016. Effect of the spectral quality and intensity of light-emitting diodes on several horticultural crops. HortSci. 51:268-71.

Wang J, Lu W, Tong Y, Yang Q, 2016. Leaf morphology, photosynthetic performance, chlorophyll fluorescence, stomatal devel- opment of lettuce (Lactuca sativa L.) exposed to different ratios of red light to blue light. Front. Plant Sci. 7:250.

Yao X, Liu X, Xu Z, Jiao X, 2017. Effects of light intensity on leaf microstructure and growth of rape seedlings cultivated under a combination of red and blue LEDs. J. Integr. Agric. 16:97-105. Yorio NC, Goins GD, Kagie HR, Wheeler RM, Sager JC, 2001. Improving spinach, radish, and lettuce growth under red lightemitting diodes (LEDs) with blue light supplementation. HortSci. 36:380-3. 